\title{
Casting Simulation of Automotive Wheel Rim Using Procast
}

\author{
K. Srinivasulu Reddy \\ Department of Mechanical Engineering, Sreenidhi Institute of Science \& Technology, Hyderabad, India
}

\begin{abstract}
Aluminium wheel rims used in transport vehicles are commonly produced by gravity die casting. Casting simulation studies are used to improve the quality of casting and to predict shrinkage, porosity and mechanical characteristics. Various FEM and VEM based casting simulation softwares are widely used in foundry. This paper discusses casting simulation of automobile wheel rim using ProCast. Solidification behaviour of the material and detection of hot spots in castings is studied and redesigned to eliminate these defects.
\end{abstract}

Keywords: aluminium alloy wheel, casting simulation, ProCast software.

\section{Introduction}

Wheel rims are manufactured by either casting or forging. Cast aluminium alloy based wheel rims are of high strength, light in weight and flexible to repair compared to forged rims. ProCAST is a three dimensional solidification and fluid flow software package used to perform numerical simulation of molten metal flow and solidification phenomena in various casting processes, primarily die casting (gravity, low pressure and high pressure die casting) and sand casting. It is particularly helpful for foundry applications to visualize and predict the casting results. Cast and mold design is transformed into a 3D model and imported into ProCAST. Simulation of mould filling and solidification of alloy wheel castings are carried out.

\subsection{Casting Process Modeling}

Generally the simulation software has three main parts shown in Figure1.

Preprocessing: the program reads the CAD geometry and generates the mesh,

Main processing: adding of boundary conditions and material data, filling and temperature calculations,

Post processing:solver, evaluation.

Figure 1 is the tree diagram for system of simulation \& Figure 2 shows 3D model of wheel rim CAD model and for which simulation tools are utilized to improve the casting process design. Computer simulation based on the design procedures described above have been implemented. Let's consider automotive wheel casting made of Aluminium alloy (A195.5-Cu4.5) for the present study which is widely used in automobile industry. Figures.3\&4 shows the 3D model of initial \& modified gating systems. During simulation of the gravity die casting process, mould filling and solidification processes are examined and optimized.

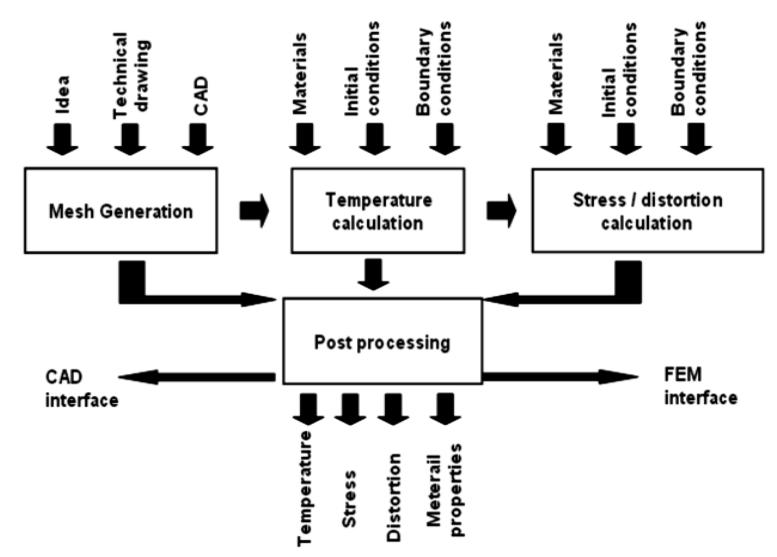

Fig.1.System of simulation

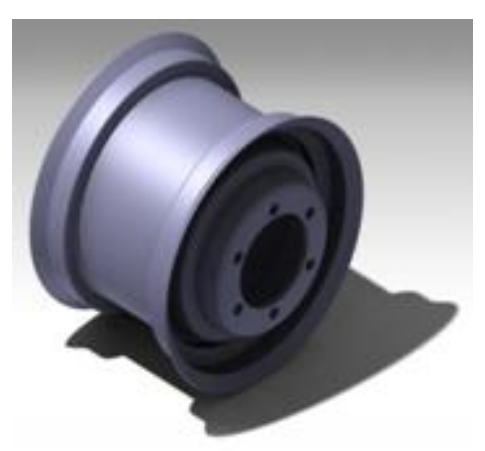

Fig 2 3D model of wheel rim 




Fig.3 3D model of initial gating system



Fig.4 3D model of modified gating system

\section{Methodology}

Methodology adopted in this work is simulation of solidification of aluminium alloy castings and analyze the results obtained after solidification. Casting parameters are optimized in order to achieve better properties. The procedures are mainly divided into three stages. They are Simulation Preparation, Computer Aided Simulation on ProCAST, and Analysis. Each stage contained several steps. We have followed this operation flow to try and examine different influencing factors, such as molten metal temperature, mould material, inlet velocity, and substrate pre-heating temperature. Figure.5 shows the entire methodology followed in the present work.

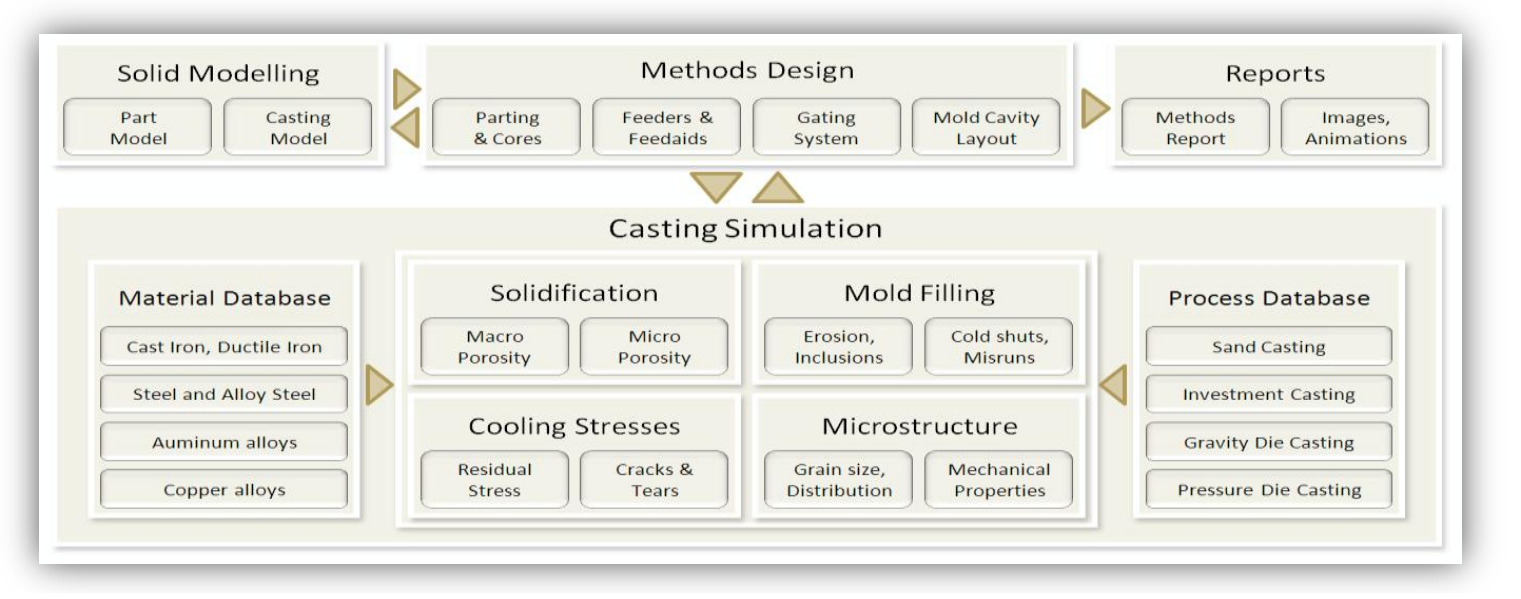

Fig.5 Methodology

\subsection{Mould Filling}

\section{Results And Analysis}

Mould filling part is carried out by the software based on the given inputs to it in boundary conditions menu. The velocity of the molten metal can be regulated by the user as per the material of the component. Procast simulation solver is used for mould filling and solidification processes at the same time. The discussion about mould filling is based on ProCAST simulation results. The mould filling processes of the initial and modified gating systems are shown in figures $6 \& 7$. It is found that for every succession of one second, fraction of solid and its temperatures are changing which encompasses pouring basin, sprue, runner system, gatings, casting and feeder. Figures. 8 \& 9 shows that down sprue and feeder are filled up simultaneously since their dimensions and shapes are very similar. Though the down sprue is the entrance of the molten metal, it was not filled up or completely wetted during the mould filling of cavity. Generally, the mould filling is successful as a result of proper design of straight runner system. It can be seen that the straight runner and gatings are filled up with in the first few second.

\subsection{Solidification \& Various Gating Systems}

For the cast aluminium alloy, solidification will start when the temperature drops below $1360^{\circ} \mathrm{C}$, and fully completed beneath $700^{\circ} \mathrm{C}$. Solidification is a result of heat transfer from internal casting to external environment. The heat transfer from the interior of the casting has to go through the various routes[1].

1. Internal liquid convection above liquidous temperature during mould filling.

2. The solidified metal conduction after complete solidification achieved throughout the bulk of casting.

3 . The heat conduction at the metal-mould interface. 
4. Heat conduction within the mould.

5. Convection and radiation from mould surface to the surrounding.

In the present case we compare the solidification simulation results of the automotive wheel rim castings at different time intervals and different gating systems as shown in the Figures.6\&7. Solidification time is proportional to volume to surface area ratio (modulus of casting)[2].Therefore the faster solidification rate at the runner tip is expected. The mould cavity which is in the center of sand mould has the longest solidification time.

Since there are long list of possibilities for a gating system of a particular casting, various gating systems were tried and tested in the ProCAST software[3]. One of those gating system with ingates settling all around the casting can be seen in the figure 6 . Molten metal is poured at a temperature of $1200^{\circ} \mathrm{C}$ with a yield of $60 \%$. A defect usually seen in plate castings is the free end distortion which is avoided through an improvised gating system. The main defect with this gating system is that the ingates solidify before the molten metal reaches the mould thereby providing no inlet to the mould and leading to a partial filling for the casting.

Moreover with such a gating system high turbulence is seen as in the figures $6 \& 8$. Hence, a remedy for such defect would have been to increase the temperature of the pouring molten metal so that the molten metal reaches the cavity and then solidifies. A Simulation is again done at $700^{\circ} \mathrm{C}$ and a defect free casting is obtained during the simulation processes. Accordingly, the turbulence levels are quite high in the initial gating system and the stresses in the casting are quite high after the solidification. A modified gating system is prepared and gating calculations are performed with a yield of $80 \%$. Once simulation is complete, a defect free casting is obtained with a yield of $80 \%$.

The fraction of solid and liquid metal in the mushy zone is a function of time and temperature. When the last drop of liquid metal is crystallized into solid, the solidification process is completed. Temperature range at the start of mould filling to the end is same in initial gating system. In the modified gating system the temperature variation between nodes at the start seems to be non-uniform but at the end of solidification it is uniform. Shrinkage porosity in initial gating system and modified gating system are shown in figures $8 \& 9$. It can be seen that shrinkage porosities are eliminated in the modified gating system.

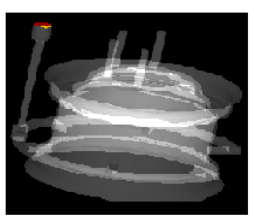

STEP :0

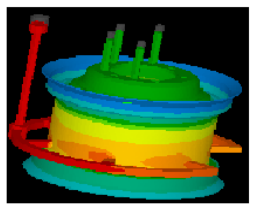

STEP :1000

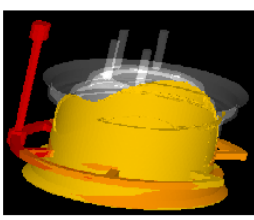

STEP :500

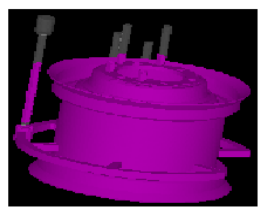

STEP :2000

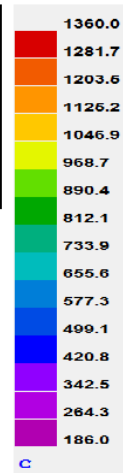

Fig 6: Mould filling and Temperature variation
of initial gating system at various stages resp.
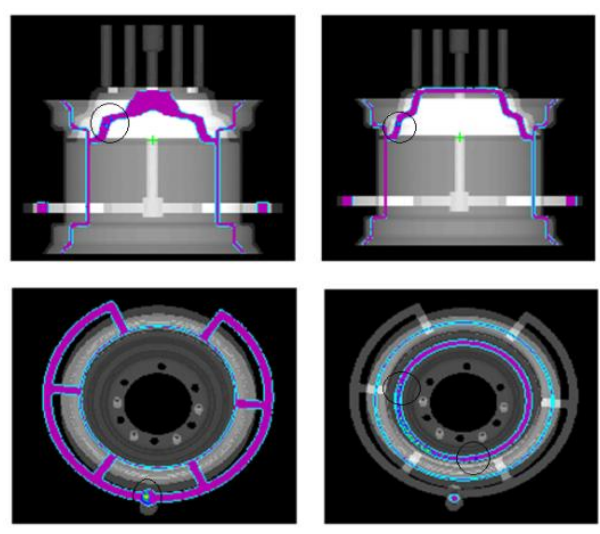

Fig. 8 Shrinkage Porosity in initial gating system at various spots.



STEP : 0



STEP : 500

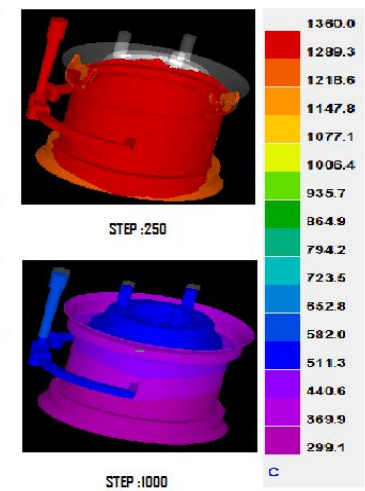

Fig 7: Mould filling and Temperature variations of modified gating system at various stages resp.
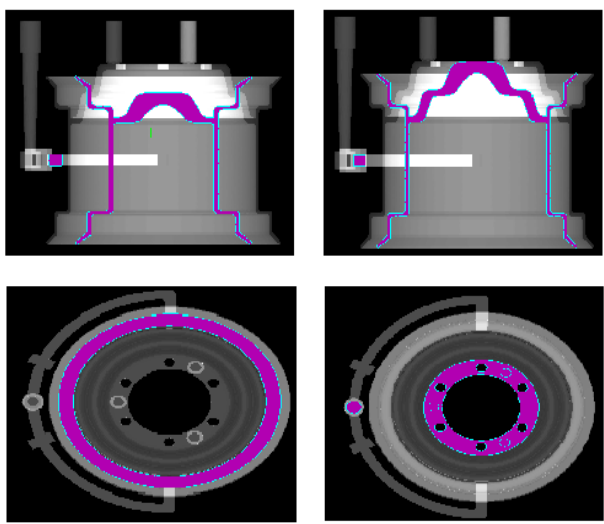

Fig.9 Shrinkage Porosity is eliminated in modified gating System. 


\section{Conclusions}

The main conclusions that can be drawn from this study are:

1. We can replace trial and error casting procedures with simulation software which involves virtual process can be able to utilize our resources efficiently.

2. Simulation tool used has the flexibility of visualizing and analyzing the processes of mold filling and solidification at a time with high resolution.

3. Simulation tool can be successfully used to identify critical locations, filling pattern and solidification related problem areas in the casting.

4. Simulation tool identifies the defects after solidification like shrinkage porosity, distortion, warm holes etc.

5. Defects can be shown in numerical values or in line diagrams at specified nodes.

\section{References}

[1]. M.R Bharkudarov, C.W Hirt (2005), Casting simulation: mould filling and solidification- Benchmark calculations using flow-3d.

[2]. Ravi, B (2005), Metal Casting - Computer AidedDesign and Analysi, Prentice Hall of India Private Limited,New Delhi

[3]. Viswanathan, W.D.Porter (2000), FeedabilityAnalysis and Optimization Driven by Casting Simulation,Indian foundry journal, 53(6), 71-78, 200

[4]. Application of Commercial Software Package "ProCAST" to the Prediction of Shrinkage Porosity in Investment Castings. www.mmat.ubc.ca/databases/Details.asp?id=354, accessed during February, 2011 . 